\title{
Acute fulminating intrapulmonary haemorrhage in Wegener's granulomatosis
}

\author{
TC STOKES, BG MCCANN, RT REES, EH SIMS, BDW HARRISON \\ From the Departments of Chest Medicine, Pathology, Oral Surgery, and Genitourinary Medicine, United \\ Norwich Hospitals, Norwich
}

Diffuse pulmonary capillaritis is a rarely described feature of Wegener's granulomatosis. We report a case in which this appears to have been the cause of the acute fulminating course of the disease.

\section{Case report}

A 63-year-old retired school caretaker was admitted to hospital with a three-week history of painful mouth ulceration and hoarseness. He had a cough productive of blood-streaked sputum and had become increasingly breathless on exercise over the same period. He had mild generalised joint pains and had lost $7 \mathrm{~kg}$ in weight.

A routine chest radiograph in 1967 was normal. A further radiograph in 1974 showed some ill-defined shadowing at the right apex. Tomography showed scarring consistent with old tuberculosis, and the lesion did not progress. In 1978 he was treated for bilateral uveitis. In 1979, one year before his admission, a miniature radiograph, requested because of "recurrent chest infections" and haemoptysis, showed no change since 1974, and his symptoms settled.

There was no significant family history or occupational exposure to noxious or allergic agents. He smoked 30 cigarettes a day. On questioning he admitted that genital ulcers had developed four weeks previously.

Physical examination revealed a bright, cheerful man who was thin and anaemic. He had painful ulcers on the soft palate, gums, penis, and scrotum. There were inspiratory crackles at the right lung base. The liver edge was just palpable. The chest radiograph showed bilateral reticulo-nodular shadowing, more marked on the right side. A cavitating lesion was noted at the right apex.

Further investigations showed a haemoglobin of $7 \cdot 3$ $\mathrm{g} \mathrm{dl}^{-1}$ with a microcytic film; white cell count $11 \cdot 3 \times 10^{9} \mathrm{I}^{-1}$ with normal differential; ESR $143 \mathrm{~mm} \mathrm{hr}^{-1}$; blood urea $14.3 \mathrm{mmol}^{-1}$; electrolytes and liver function tests normal; urine granular casts only; blood, sputum, and urine cultures negative; sputum smears for acid-fast bacilli negative; rheumatoid factor, ANF, anti-DNA antibody, and Australia antigen negative; serum immunoglobulins normal; viral titres negative; total haemolytic complement low but $\mathrm{C} 3$ normal; serological tests for syphilis negative. A biopsy of a buccal ulcer was taken.

At this stage our differential diagnosis included tuberculosis, Behçet's disease, polyarteritis nodosa, of Chest Medicine, West Norwich Hospital, Bowthorpe Road, Norwich NR2 3 TO.
Wegener's granulomatosis, Goodpasture's syndrome, and disseminated carcinoma.

On the second hospital day he became very breathless and his haemoglobin had fallen to $5.9 \mathrm{~g} \mathrm{dl}^{-1}$. Five units of blood were transfused and his haemoglobin rose to $11.0 \mathrm{~g}$ $\mathrm{dl}^{-1}$. Hydrocortisone, $100 \mathrm{mg}$ six-hourly, and antituberculous chemotherapy was begun. The next day he was still more breathless, tachypnoeic, and cyanosed. Breathing air his $\mathrm{Po}_{2}$ was $3.7 \mathrm{kPa}, \mathrm{PCO}_{2} 4 \cdot 1 \mathrm{kPa}$, and pH 7.36. The $\mathrm{Po}_{2}$ did not rise on $60 \%$ oxygen. The chest radiograph showed extensive consolidation of both lungs (fig 1); his heart size remained normal. The haemoglobin had fallen to $5 \cdot 0 \mathrm{~g} \mathrm{dl}^{-1}$.

A diagnosis of intrapulmonary haemorrhage was made and continuous positive pressure ventilation was begun. Copious amounts of blood were aspirated via the endotracheal tube and repeated blood transfusions were necessary. At this stage the results of the mucosal biopsy showed a necrotising vasculitis. Intravenous cyclophosphamide $4 \mathrm{mg} \mathrm{Kg}^{-1}$ daily was begun as additional treatment of his fulminating systemic vasculitis. However,

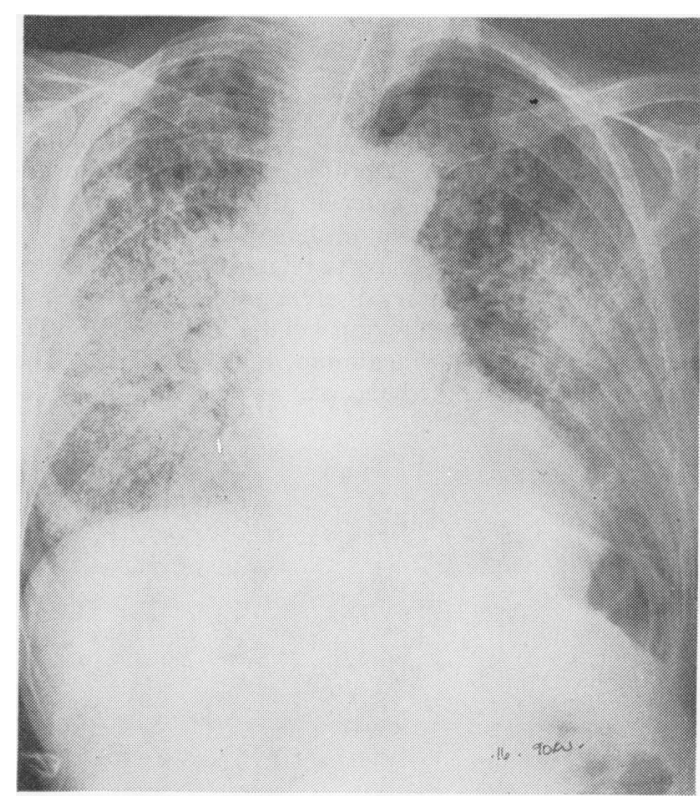

Fig 1 Chest radiograph on third hospital day showing widespread consolidation in both lungs. 


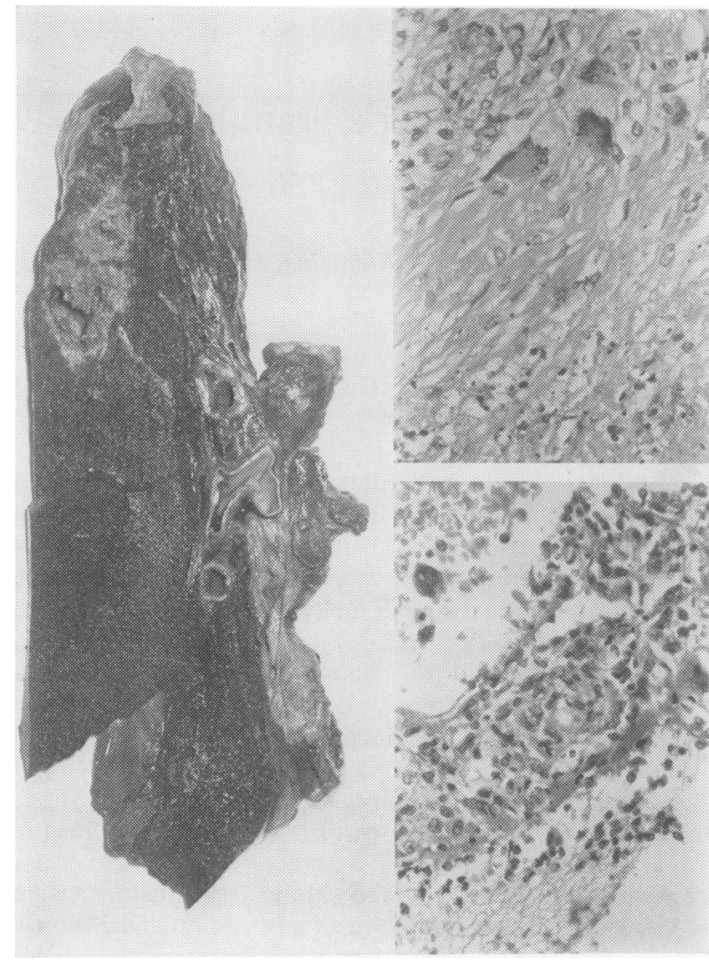

Fig 2 Cavitating mass in the upper lobe of the right lung. The lung is entirely haemorrhagic. Upper insert shows granulomatous reaction with giant cells. Lower insert shows alveolar spaces filled with blood, and acute capillaritis.

despite administration of $100 \%$ oxygen, it was impossible to raise the arterial $\mathrm{Po}_{2}$ above $7.5 \mathrm{kPa}$. He remained hypoxic, renal function deteriorated, and electrocardiographic changes of an anterior myocardial infarction appeared. He died on the ninth hospital day.

At necropsy there was massive bilateral intrapulmonary haemorrhage and a solitary discrete grey-white cavitating mass in the sub-apical region of the right upper lobe measuring $5 \mathrm{~cm}$ in its maximum diameter (fig 2). The intrapulmonary haemorrhage was associated with wide- spread necrotising alveolar capillaritis (fig 2). Sections of the cavitating lesion showed massive necrosis of the lung, accompanied by arteritis and venulitis. A granulomatous reaction featuring histiocytes and giant cells encompassed the necrotic focus (fig 2). Necrotising arteritis was also found in the spleen. The kidneys showed focal necrotising glomerulonephritis. Granular deposition of $\mathrm{IgG}$ and complement on glomerular capillary basement membranes (but not in the alveolar capillaries) was demonstrated using immunofluorescent techniques on frozen sections. An unrelated finding was a recent myocardial infarct, the result of coronary thrombosis and atherosclerosis. The combination of the pulmonary lesion, systemic vasculitis and focal glomerulonephritis indicated Wegener's granulomatosis.

\section{Discussion}

Acute massive pulmonary haemorrhage is a rarely described feature of Wegener's granulomatosis. Fauci and Wolf ${ }^{1}$ reported a patient who died of acute pulmonary haemorrhage, and Kjellstrand $e t a l^{2}$ described a patient with sudden onset of copious haemoptyses and almost total opacification of the lungs on chest radiograph, who responded to anti-human lymphoblast globulin, methylprednisolone and azathioprine. In neither case is there a report of the pathological changes in the lung. Alveolar capillaritis is not a well-documented feature of Wegener's granulomatosis. Liebow ${ }^{3}$ does not refer to it in his detailed review of pulmonary angiitis and granulomatosis and it is only briefly mentioned by Spencer. ${ }^{4}$ In the case reported here, alveolar capillaritis was the dominant pathological lesion and we believe it was responsible for the massive pulmonary haemorrhage and fulminating course of the disease.

\section{References}

${ }^{1}$ Fauci AS, Wolf SM. Wegener's granulomatosis: studies in eighteen patients and a review of the literature. Medicine $1973 ; 52: 536-61$.

${ }^{2}$ Kjellstrand CM, Simmons RL, Uranga VM, Buselmeier TJ, Najarian JS. Acute fulminant Wegener's granulomatosis. Arch Intern Med 1974;134:40-3.

${ }^{3}$ Liebow AA. The J Burns Amberson Lecture-Pulmonary angiitis and granulomatosis. Am Rev Respir Dis 1973; 108:1-18.

${ }^{4}$ Spencer H. In: Pathology of the lung. Third edition. London: Pergamon Press, 1977. 